\title{
Negation, des-Indefinites in French and Bare Nouns across Languages
}

\author{
Carmen Dobrovie-Sorin
}

\section{Introduction}

This article is concerned with the contrasting behavior of Bare Noun Phrases (BNs) and the French indefinites headed by des/de la/du (des-indefinites henceforth) with respect to negation: ${ }^{1}$ whereas the former must take narrow scope with respect to a negative quantifier, the latter cannot do so in canonical contexts. This difference cannot be accounted for within the wide-spread view that des-indefinites have the same semantic type as BNs interpreted existentially (in languages such as English, Romanian or Spanish). But importantly, both des-indefinites and BNs qualify as "weak" (in Milsark's 1977 sense), which means that we need to assume two distinct types of denotation for weak indefinites. The solution will be to distinguish between property-denoting expressions (suited for B Ns) and D Ps that denote weak existential quantifiers (suited for des-indefinites). The insensitivity to negation of BNs is due to the fact that no existential Q (i.e., quantifier) is present at LF (Logical Form). The incompatibility between a negative quantifier and des-indefinites will be explained as follows: (i) polyadic negative quantification is needed for the intended reading; (ii) polyadic quantification obtains at LF only if Collins and Postal's (2004) "Determiner Sharing" holds in the syntax; (iii) Determiner Sharing does not obtain between the positive existential Q denoted by des-indefinites and a negative existential Q.

The resistance to negation exhibited by des-indefinites can be referred to by using the label Positive Polarity Item (PPI). BNs differ from des-indefinites in being insensitive to negation (they are neither PPIs nor Negative Polarity Items (NPIs)). Section 2 will provide the empirical data in favor of these generalizations. Section 3 proposes distinct denotations for des-indefinites and BNs: the former denote weak existential quantifiers, whereas the latter denote

1 Schurr, in this volume, compares bare nouns and partitive-marked nominals in Romance in a usage-based account. Cf. also Garzonio and Poletto (2020) for an analysis of indefinite (partitive) objects under negation in the Northern Italian dialectal area. 
properties. Section 4 shows that this difference in denotation corresponds to a difference in syntactic representations: des-indefinites are full DPs, whereas BNs lack the DP level of representation. Section 5 explains why des-indefinites are PPIs (cannot take narrow scope with respect to negation).

In this section I show that French des-indefinites qualify as Positive Polarity Items (PPIS). I will review the various tests that support the PPI status of des-indefinites, and I will show that the "exceptional" contexts in which desindefinites can take narrow scope with respect to negation are exactly those contexts in which other PPIs can do so. This means that such exceptional contexts do not question the PPI status of des-indefinites. I will then turn to the BNS found in Romanian or Spanish, which are insensitive to negation. This contrasting behavior strongly suggests that des-indefinites cannot be assumed to have the same semantic type as BNs, despite the fact that both of these two nominals are weak indefinites. Instead, I will postulate the existence of two distinct types of weak indefinites, which only differ regarding their behavior with respect to negation.

\subsection{Des-indefinites and Negation: The Core Data}

The shift from des to invariable $d e^{2}$ illustrated below is a very basic fact in French, which is mentioned in any grammar of French, as well as in more formal approaches to "partitives" (Gross 1967; Attal 1976; Wilmet 1977 and Kupferman 1979):

\section{(1) French}

a. Jean a filmé des ours. Jean has filmed PA.PL bears 'Jean filmed some bears.'

b. Jean a acheté du vin. Jean has bought PA.M.SG wine 'Jean bought some wine.'

2 As we will see in Section 5.1, these $d e$-indefinites are analogous to those any-N Ps that occur in the scope of negation. 


\section{(2) French}

a. Jean n' a pas filmé d' ours/ * des ours. Jean NEG has not filmed DE bear/ PA.PL bears 'Jean didn't film any bear.'
b. Jean n' a pas acheté de vin/ *du vin. Jean NEG has not bought DE wine PA.M.SG wine 'Jean did not buy any wine.'

These examples show that des-indefinites cannot take narrow scope with regard to sentential negation.,4 The indicated unacceptability of the $d e s / d u$ versions of the examples in (2) is due to the fact that in run-of-the-mill contexts des-indefinites are necessarily weak, which means that they strongly resist wide scope readings. It is only with well-chosen lexical items (both verbs and nouns) that wide scope is marginally possible (see footnote 14 in Section 2.4).

In Sections 2.2 and 2.3, I will describe a number of "marked" contexts in which des-indefinites can scope under negation. As will be made clear there, such contexts do not invalidate the following generalization (the relevance of restricting our attention to local narrow scope will become relevant in Section $2.2)$ :

(3) In standard French, des-indefinites cannot take local narrow scope with regard to negation (in unmarked contexts).

3 In some dialects of French, des/de la/du can be interpreted in the scope of negation. Insensitivity to negation can also be observed in colloquial speech even in those regions where the des/de alternation is used by the majority of speakers (see the corpus OFrom hosted at the University of Neuchâtel in Switzerland; see Stark and Gerards, this volume, on Francoprovençal). It should however be observed that the use of the des/de alternation is fully colloquial in standard French. As such, the use of de instead of des under negation is to be distinguished from, for instance, the agreement of past participles (see les tasses que j'ai prises 'the cups that I have taken.F.PL' vs. the colloquial les tasses que j'ai pris 'the cups that I have taken', which is less naturally used by French speakers). Thus, highly educated native French speakers (among others, CNRS researchers or Professors at the University) frequently disregard the norm concerning past participle agreement in oral speech but always use de under negation.

4 Interestingly, Italian seems to be similar to French in showing an alternation between dei in positive contexts and B PS and BMNS when narrow scope with respect to negation is intended. Giusti (this volume) briefly discusses the scope properties of nominals with a "partitive article" in Italian and Italo-Romance, but she only takes into account contrastive contexts (see Section 2.3 below). 
Let me draw the attention of the reader that the ban on narrow scope with respect to negation does not correlate with narrow scope with respect to modals or intensional verbs. Indeed, on their unmarked reading, des-indefinites are weak indefinites and, as such privilege narrow scope interpretations (with respect to quantificational subjects, modals or intensional verbs):

(4) French

a. Jean doit lire des romans. MUST $>$ des Jean must read PA.PL romans 'Jean must read some novels.'

b. Jean cherche des élèves lookfor $>$ des Jean looks.for PA.PL pupils 'Jean is looking for pupils.'

The fact that narrow scope with respect to negation is not related to narrow scope in general is by no means an idiosyncratic property of des-indefinites but is instead quite general across languages for indefinites headed by overt Determiners (BNs, which are different, will be examined in Section 2.5). ${ }^{5}$ Thus, most indefinites in object position allow a narrow scope interpretation with respect to modals and intensional verbs but disallow narrow scope with respect to negation. To make this point as clear as possible it is useful to consider those indefinites that preferentially take narrow scope, for example, the unstressed $s m$ in English. The point is clearer in the sense that narrow scope with respect to negation is banned despite the fact that narrow scope is preferred, or even obligatory, with respect to other operators:
(5) a. John must read sm novels.
(MUST > sm)
b. John is looking for sm students.
$($ look for $>\mathrm{sm})$
c. John didn't read sm novels.
$\left({ }^{*}\right.$ not $>$ sm)

Note now that the impossibility stated in (3) above is exactly the definition of PPIS:

(6) A PPI is a constituent that cannot take local narrow scope with regard to negation.

5 Also insensitive to negation are des-indefinites in the dialects described in footnote 3 . 
Some-indefinites in English constitute the paradigmatic example of PPI indefinite to be found in the current literature. Regarding narrow scope, the data are the same as (5), where the unstressed version of some was used. Wide scope readings are however preferred with the stressed some, an issue to which we will come back in Section 2.4. Taken together, (3) and (6) amount to saying that des-indefinites are PPIs.

The PPI status of des is confirmed by the fact that it is banned not only from the scope of a negated main predicate (which in French is signaled by pas), but also from the scope of the antiadditive operator sans 'without':6

(7) *Jean est venu sans des livres /du café.
Jean is come without PA.PL books PA.M.sG coffee

These examples are interesting because they invalidate a plausible explanation for the des/de alternation that would build on the idea that the use of the invariable $d e$ is due to some morphosyntactic requirement of the negation particle pas itself.

To the best of my knowledge the PPI status of $d e s / d e l a / d u$ has not been observed in previous work on French des-indefinites. ${ }^{7}$ The reason may be a tacit assumption that is explicitly mentioned in passing by Le Bruyn (2010): "articles are not PPIs", a generalization that Le Bruyn illustrates with an example built with the singular indefinite article $a$ in English: ${ }^{8}$

John didn't see a bear/cat/car.

Since according to Le Bruyn des/de la/du are articles, they would not qualify as PPIS.

6 Note on the other hand that the presence of pas seems nevertheless crucial for the analysis of the invariable $d e$. Indeed, the invariable $d e$ is itself banned from the scope of sans 'without', which only allows BNs (which in French are disallowed in argument positions (unless they are coordinated, see Roodenburg 2004) but allowed with some prepositions):

(i) *Jean est venu sans de livres/ de café.

Jean is come without of books/ of coffee

(ii) Jean est venu sans livres/ café.

Jean is come without books/ coffee

'Jean has come without books/coffee.'

7 In particular, des-indefinites are not mentioned among the items that are identified as PPIS in Tovena et al. (2004), a well-informed and comprehensive chapter on "Polarity Sensitive Items" in Corblin and De Swart (2004).

8 But see Van den Wyngaerd (1999) who argues that $a(n)$ in English is a PPI. 
The opposite view is expressed by Homer (2011) in a footnote:

(9) The PPI phenomenon is extremely robust across languages: to my knowledge, the unacceptability of indefinites-otherwise acceptable in simple positive sentences - under a clausemate negation is universal.

Examples of the type in (8) do not constitute evidence against the PPI status of the singular indefinite, because in such examples the article has a "minimizing" use, as suggested by the fact that in run-of-the-mill examples, $a$ changes to any:

(10) a. John saw a bear/cat/car.

b. John didn't see any bear/cat/car.

Now, if the singular indefinite article is a PPI, there is no reason to deny the PPI status of des/de la/du in French.

The preceding remarks are not meant to criticize Le Bruyn (2010), who is not interested in PPIs. Homer (2011) himself does not mention des/de la/du indefinites at all. My only point in invoking these authors is that the PPI status of $d e s / d e l a / d u$ is either ignored or questioned by the current literature. More importantly, regardless of the labels we may want to use, the alternation between $d e s / d e l a / d u$ in positive assertions vs bare $d e$ in negative assertions, which is a core fact of French grammar, has been left aside by most (to my knowledge all) of the recent developments in formal semantics.

\subsection{When PPIS can Scope under Negation}

There are well-known contexts in which PPIs of the some type can occur in the scope of negation (see in particular Jespersen 1917; Szabolcsi 2004 and Larrivée 2012). Consider (11) from Szabolcsi (2004, (24), (7), and (23)):
(11) a. Idon't think that John called someone.
(not $>$ some)
b. He found something.
Wrong! He DIDn't / DID NOT find something. (not > some)
c. John didn't show every boy something. $\quad$ (not $>$ some)

The following examples show that in the same contexts, des can take narrow scope with respect to negation: ${ }^{9}$

9 Both Szabolcsi (2004) and Larrivée (2012) assume that DPs of the form some NP, as in some students, some wine are parallel to somebody/someone/something, but only the latter appear 
(12) Je ne pense pas que Jean ait écrit des romans. I NEG think not that Jean has. SBJV written PA.PL novels 'I don't think Jean wrote novels.'

(13) a. Jean a écrit des romans. Jean has written PA.PL novels 'Jean wrote some novels.'

b. Non, Jean n' a pas écrit des romans. non Jean NEG has not written PA.PL novels 'Jean did Noт write novels.'

(14) Tu ne gagneras pas del' argent en composant dela musique. you NEG will.win not PA.SG money by composing PA.F.SG music 'You will NOT earn ("some) money by composing music.'

(15) a. Jean ne dit pas souvent des bêtises. Jean NEG says not often PA.PL stupid.things 'Jean doesn't often say (*some) stupid things.'

b. Jean n' a pas envoyé des livres à tous les élèves. Jean NEG has not sent PA.PL books to all the students 'Jean hasn't sent ("some) books to all the students.'

What the examples above have in common is that the relation between negation and des is not local. ${ }^{10}$ Thus, in (12), negation and des do not belong to the same minimal clause. The examples in (13)-(14) illustrate denial and emphaticcontrast contexts, which might be analyzed as metalinguistic negation (Horn

in the examples that these authors use in order to illustrate the various generalizations. In the main text I build des-counterparts of some of the examples of these authors. In the translations I use BNs, the some-NPs being inappropriate. The difference between some NPS and the pronominal series of some is arguably due to differences in their respective scalar properties, but this has not been addressed in the previous literature (this issue is currently under investigation in joint work with Tabea Ihsane).

10 It is interesting to observe that scalar properties seem to be relevant for the "marked" non-local narrow scope with respect to negation discussed in the present subsection but not for the "unmarked" local scope with respect to negation: some NPS, des NPS as well as the pronominal series somebody/someone/something and their French counterparts quelqu'un/quelque chose are alike in being unable to scope under local negation in unmarked contexts. 
1989) or as a particular type of extraclausal negation (Szabolcsi 2004, and references quoted there). Finally, examples $(15 \mathrm{a}-\mathrm{b})$ illustrate the case in which non-locality is induced by the presence of an intervening operator (the adverb souvent 'often' or the universal quantifier) at the level of LF: note that in $(15 \mathrm{~b})$, tous 'all' is not a linear-order intervener; but at LF, tous scopes in between pas and des (the sentence means something like it is not to all students that John sent books'). According to Szabolcsi (2004), examples of this type (built with something, someone) do not constitute evidence against the PPI status of some in English provided that the relevant constraint on PPIs is defined in terms of immediate (meaning "local") narrow scope rather than just narrow scope.

There is, however, a group of examples in which PPIs can appear in the immediate scope of negation, as in (16) (from Szabolsci 2004, (33), (36), (37), and (39)).

(16) a. Idon't think that John didn't call someone.

b. I regret that John didn't call someone.

c. If we don't call someone, we are doomed.

d. Only John didn't call someone.

Again, we find that des-indefinites are themselves allowed in these contexts:

(17) a. Je ne crois pas qu' il n' a pas mangé du I NEG believe not that he NEG has not eaten PA.M.SG chocolat.

chocolate

'I don't think he ate chocolate.'

b. Je regrette qu' il n' a pas écrit des romans. I regret that he NEG has not written PA.PL novels 'I regret that he didn't write novels.'

c. Si Jean n' apporte pas des gâteaux, j' irai en acheter. if Jean NEG brings not PA.PL cookies I will.go PART buy 'If Jean doesn't bring cookies, I'll go buy some.'

d. Seulement Jean n' a pas apporté des gâteaux. only Jean NEG has not brought PA.PL cookies 'Only Jean didn't bring cookies.' 
The hallmark of these examples is that the sequence [Negation $>$ PPI] occurs in the scope of a higher operator, such as a negated belief verb, regret, the conditional or only.

Larrivée (2012) observes two further contexts in which some is allowed to take narrow scope with respect to negation, namely negated questions (18) and the complement of the fact (19). In these contexts also, des-indefinites pattern with some-indefinites:

(18) $N^{\prime} \quad$ a t-il pas écrit des romans?

NEG has he not written PA.PL novels

'Didn't he write (some) novels?'

(19) Le fait qu' il $n^{\prime}$ a pas écrit des romans... the fact that he NEG has not written PA.PL novels 'The fact that he didn't write novels ...'

Because of examples of the type in (17), Szabolcsi (2004) proposed that PPIS are doubly-negated existentials in their underlying representation. Under this hypothesis, the acceptability of (17) would be due to the presence of two downward monotonic operators, each of which would license one of the two negations of the some-indefinite." This proposal was criticized by Larrivée (2012), who proposes an alternative explanation, based on a principle that uses the notion of "activated proposition" (Dryer 1996): all the contexts listed above are analyzed by Larrivée as triggering the activation of propositions; and when that happens, it is the whole proposition that is brought "into the focus of negation, which [therefore] does not interact directly with the PPI to produce infelicitous interpretations." (Larrivée 2012, 869). In this article I will not be interested in the "rescuing" contexts briefly presented above. The discussion in this section was simply meant to make it clear that I am aware of these examples, but that I do not consider them to be counterevidence against the PPI status of des-indefinites. Nor do I think that the analysis of these examples bears on the analysis of the run-of-the-mill examples in which des must be replaced by $d e$.

11 The unacceptability of narrow scope of some with respect to negation in unmarked contexts (see $(5 \mathrm{c})$ ) would be due to the fact that only one of the two underlying negative elements is licensed. In the absence of any negation outside the some-indefinite, the two internal negations cancel each other, yielding acceptability. 


\subsection{When des (But Not some) can Scope under Negation}

Quite interestingly, there is still another context in which des-indefinites can take narrow scope with regard to negation: ${ }^{12}$

(20) French

a. Jean n' a pas filmé d' ours/ des ours mais des Jean NEG has not filmed DE bear/ PA.PL bears but PA.PL pandas.

pandas

'Jean did not film bears, but pandas.'

b. Jean n' a pas acheté de vin/ du vin mais $d u$ Jean NEG has not bought DE wine/ PA.M.SG wine but PA.M.SG whisky.

whisky

'Jean did not buy wine, but whisky.'

In the English counterparts of these examples, the des-indefinites must be translated by BPS and BMNs; some is unacceptable or at best marginal (in a denial-type of context):

(21) a. ?*John hasn't filmed some bears, but some pandas.

b. John hasn't filmed bears, but pandas.

The fact that some is disallowed in this type of example indicates that the reason for the acceptability of des cannot be attributed to the general behavior of PPIs of the some type. The fact that des-indefinites need to be translated by вPs and BMNs suggests that in this particular context, des-indefinites need to be analyzed as B Ps and BMNs, not as some indefinites.

12 As far as I could gather from informal questionnaires, the Italian data are by and large similar: if contrastive contexts (the only ones mentioned in Cardinaletti and Giusti (2017)) are left aside, dei/del/della cannot be interpreted in the scope of negation. I could nevertheless find a counterexample in Le Bruyn $(2010,101)$, according to whom the example in (i) can take the two interpretations indicated below:

(i) Non ho visto dei bambini.

not [I].have seen PA.PL children

'I haven't seen any children.'

'There are some children that I haven't seen.'

Dei is known to take wide scope easily (Chierchia 1998; Storto 2003 and Zamparelli 2008), unlike des in French. But the narrow scope with regard to negation (the "any" reading above) is much less acknowledged. Cf. also footnote 4 above. 
The example in (20a) does not deny the existence of a filming event but only the fact that the filming event involved bears; it asserts the existence of a pandafilming event. Compare the examples in (2), which assert that there was no filming of bears and no buying of wine. In unmarked contexts, such examples entail that there was no filming and no buying event.

This informal description of the meaning of $(20)$ suggests that it is only the des-indefinite that scopes under negation, to the exclusion of the main predicate. These scope relations can be overtly observed in clefts:

(22) Ce ne sont pas des ours/ *d' ours que Jean a filmé. that NEG are not PA.PL bears *PA bears that Jean has filmed 'It's not (*some) bears that Jean has filmed.'

In this example, the main predicate is outside the scope of pas, whereas des itself is inside the scope of pas. The unacceptability of the invariable $d e-$ indefinite (d'ours) indicates that a negated copula not only allows for des, but also disallows (does not license) invariable-de indefinites. This latter observation concerns not only clefts, but is a general property of the negated copula (which to my knowledge has gone unnoticed so far):

(23) Tom et Henry ne sont pas des ours/ *d' ours. Tom and Henry NEG are not PA.PL bears/ * PA bears 'Tom and Henry are not ("some) bears.'

Note furthermore that in fragment answers, des can scope below pas:

(24) a. Qu'est-ce que tuvoudrais manger? 'What is it that you would like to eat?'

b. Pas des carottes/ de carottes not PA.PL carrots/ PA carrots 'Not ("some) carrots.'

The facts mentioned in this subsection deserve a full-length article on their own. For my present purposes it is sufficient to refine our generalizations regarding the distribution of des under negation:

(25) a. Des-indefinites cannot scope below a negated main predicate.

b. Des-indefinites can scope below a "bare" negative quantifier and below a negated copula. 
In the explanatory part of this article (essentially Section 5 ) I will propose an explanation for $(25 \mathrm{a})$ and make a suggestion for $(25 \mathrm{~b})$.

\subsection{Indefinites That Scope above Negation}

The next task is to identify some defining property of des-indefinites that would explain their PPI status (more precisely, their impossibility of taking narrow scope with respect to a negated main predicate).

Giannakidou $(2008,34)$ attributes the P PI status of the English some (as well as of its Greek counterparts examined in Giannakidou 1998, 2000) to its being allowed to take wide scope: ${ }^{13}$

(26) "Scoping above negation is the defining property of PPI-hood." Giannakidou $(2008,34)$

Szabolcsi (2004) has convincingly argued that this type of explanation cannot be correct for the English some. There is no doubt that some can scope above negation (provided that it is pronounced with emphatic stress), but this property is independent of its PPI status, which is concerned with narrow scope. The crucial fact is that the impossibility of the narrow scope of some with respect to negation contrasts with the possibility of narrow scope with respect to other operators, such as the necessity modal:

(27) a. John must have met some old friends. (some > MUST; MUST > some) b. I haven't met some students. $\quad$ (some $>\mathrm{NEG}$; * NEG $>$ some)

The possibility of some scoping under MUST shown in (27a) and the impossibility of scoping under negation shown in $(27 \mathrm{~b})$ are exactly parallel to our observations regarding des (see (4) and (2)).

Des-indefinites are more resistant to taking wide scope than some indefinites. It is only in well-chosen examples that des-indefinites can have specific interpretations, in which case they can take wide scope, and even scope above negation: ${ }^{14}$

13 A similar idea can be found in Progovac's (200o) analysis of the Serbo-Croatian PPI $n e(t) k o$ 'someone'.

14 The external reviewer of this paper points out that Galmiche (1986) argued in favor of the possibility of specific readings of des-indefinites and correlatively of the possibility of wide scope, in particular over modals, as in Berthe veut rencontrer des linguistes 'Berthe wants to meet sm linguists'. I acknowledge this possibility, but the fact that it needs to be "proved" indicates that the specific readings of des-indefinites are "marked" compared 
(28) French

a. ??Des étudiants ne sont pas venus en cours aujourd'hui. PA.PL students NEG are not come in class today 'Some students did not attend class today.'

b. ??Dans ce champ du maïs $n^{\prime}$ a pas été fauché. ${ }^{15}$ in this field PA.M.SG corn NEG has not been mown 'In this field, some corn has not been mown.'

Let me however insist on the fact that the marked possibility of wide-scoped des-indefinites is independent of their PPI status, which is only concerned with narrow scope.

In sum, for both some and des, their P P I status (impossibility of narrow scope with respect to negation) is orthogonal to the (im)possibility of wide scope and moreover, the narrow scope with respect to negation does not correlate with the narrow scope with respect to other operators. In other words, the PPI status of some and des-indefinites cannot be explained on the basis of the general scopal properties of these items.

\subsection{Bare Nouns Are Not PPIs}

Their PPI behavior distinguishes des-indefinites from BPs and BMNs, which obligatorily take narrow scope with regard to negation (Carlson 1977):

(29) a. John has(n't) read novels.

b. Mary doesn't drink/drinks milk.

In the languages in which they exist, count bare Ns, also called Bare Singulars (BSs), behave on a par with BPS and BMNs with respect to negation:

(30) Romanian

a. Ion (nu) purta cămaşă.

Ion (NEG) wore shirt

'Ion was(n't) wearing a shirt.'

to their non-specific readings. Indeed, the lexical choice of the verb, the noun, combined with pragmatic notions such as "relevance" (see also Attal 1976) are crucial for the specificity and wide scope of des-indefinites in standard French.

15 This is an example I have built on the model of the example in (i), attributed to Kleiber (1989) by Bosveld-de Smet (2004):

(i) Dans ce champ du maïs est pollué.

in this field PA.M.SG corn is polluted. 
b. Blocul ăsta (nu) are lift.

building.DEF this (NEG) has elevator

'This building has/doesn't have an elevator.'

Although some qualifications may apply, for our present purposes I will assume (for languages with articles) the generalization stated below:

(31) All existentially interpreted BNs (BPS, BMNs, BSs) take narrow scope with regard to negation.

The obligatory narrow scope of existential BNs with respect to negation has been attributed to their semantic analysis (existential quantification supplied by the main verb combined with kind-denotation (Carlson 1977) or propertydenotation (Van Geenhoven 1996) of the BN), which is also responsible for obligatory narrow scope with regard to other operators.

\subsection{Distinguishing between des-indefinites and BNS}

The data reviewed in the previous subsections show that des-indefinites and BNs form an interesting minimal pair: both types of expressions qualify as "weak" and take narrow scope (obligatorily for BNs and preferentially for desindefinites) with regard to modal operators or intensional verbs, but they differ insofar as des-indefinites cannot, whereas BNs must, take narrow scope with respect to negation.

In order to start understanding this contrasting behavior of BNs and desindefinites with respect to negation, we need to find some difference that may turn out to be relevant.

There is an obvious perceptible difference between BNs and des-indefinites: bareness of the NP (noun accompanied by certain modifiers) as opposed to the presence of extra material, the inflected elements des/de la/du themselves, preceding the NP. But the way in which this extra material is relevant for PPI status is not given on its sleeve. Following Chierchia (2006), most of the existing analyses treat PPIs as a scalar phenomenon (see in particular Nicolae 2017, on disjunction and Falaus 2018, on free choice items). Nicolae (2012) extends this treatment to the English some, but in fact only deals with the some that takes a singular NP as a complement, as in *Mary didn't meet some friend yesterday. Since the singular some is known to be different from some $\mathrm{NP}_{\mathrm{pl}} / \mathrm{NP}_{\text {mass }}$, I will not evaluate Nicolae's proposal here, assuming that it is not relevant for the analysis of des-indefinites, the meaning of which does not seem to have a scalar component.

A scalarity-based account does not seem to help explaining the PPI status of des-indefinites, because these nominals do not have any scalar properties 
that might distinguish them from BNs. I will instead show that the contrasting behavior of BNs and des-indefinites can be explained by assuming that they have different denotations (contra previous proposals, in particular Bosveldde Smet 1998; Galmiche 1986; Dobrovie-Sorin and Beyssade 2004, 2012):

(32) a. BNs are property-denoting nominals.

b. Des-indefinites are weak existential quantifiers.

The observations made in Section 2.3 above suggest the following refinement: (32b) holds when des-indefinites are interpreted in the scope of the main predicate. When occurring outside the scope of the main predicate (e.g., in clefts) or in copular constructions, the distribution of des-indefinites is different from that of some indefinites and resembles that of BNs. This suggests that in such contexts des-indefinites are property-denoting, on a par with BNs. In this article I will restrict my attention to those contexts in which des-indefinites are interpreted inside the scope of a lexical main predicate.

In Section 3 I give a brief overview of the various rules of semantic composition that have been proposed for property-denoting nominals, and I argue that a unique rule of semantic composition, Predicate Modification, should be assumed for all BNs (BSs and BPs/BмNs should be treated alike). The insensitivity with respect to negation will be explained as following rather straightforwardly from analyzing BNs as predicate modifiers of the main predicate. In the last subsection of Section 3 I introduce Dobrovie-Sorin and Giurgea's (2015) definition of the notion of weak existential quantifier, which according to (32b) is needed for the analysis of des-indefinites. In Section 4 I propose syntactic analyses of BNs and des-indefinites that correlate with the denotational distinction stated in (32). In Section 5 I show that the PPI status of weak existential quantifiers can be explained if we assume that (i) narrow scope with respect to negation involves polyadic quantification and (ii) polyadic quantification is constrained by Collins and Postal's (2014) Determiner Sharing.

In what follows, I will briefly review two semantic analyses, which were respectively proposed for BPs and BMNs on the one hand and for BSs on the other hand (Sections 3.1 and 3.2, respectively). ${ }^{16}$ In Section 3.3 I will argue that BPs

16 Because of lack of space I will not present Diesing's (1992) proposal, which relies on trans- 
and BMNs can be assumed to have the same semantics as that of Bss: they can be analyzed as property-denoting expressions that combine with the main predicate via Predicate Modification. Based on this assumption, the obligatory narrow scope of BNs with respect to negation is explained in Section 3.4. In Section 3.5 I review a third type of analysis for weak indefinites, which had been designed for в Ps and в MNs, but which I argue is suited for des-indefinites.

\subsection{Property-Denoting Arguments That Saturate Existential Predicates}

According to a widespread view, existential BPs and BMNs in Romance (and other languages which lack kind-referring BPs) are property-denoting (type $\langle e, t\rangle)$ expressions (McNally 1995, 1998a, 1998b; Dobrovie-Sorin 1997; DobrovieSorin and Laca 2003; Dobrovie-Sorin et al. 2005, 2006), despite the fact that they quite freely occur in argument positions, as in the following Romanian example: ${ }^{17}$

\section{(33) Romanian \\ Ion a citit romane. \\ Ion has read novels \\ 'Ion read novels.'}

Qua property-denoting expressions, BPs and BMNs cannot combine with the main predicate via the canonical rules of semantic composition (saturation or quantification). The most largely adopted implementation, known as "semantic incorporation" is due to Van Geenhoven (1996): the main predicate is represented as an "existential predicate", that is, a predicate that has some or all of its argument positions bound by existential closure and waits to be saturated by a property $\mathrm{P}$ that restricts the range of the relevant argument (in the following, I notate this "existential" version of the main predicate with the prime symbol):18

lating BNS (and weak indefinites in general) as free variables that get bound by vP-level existential closure. Insofar as Diesing's proposal relies on a variable bound by an existential Q, her analysis looks like a variant of an existential quantifier analysis and as such yields the wrong results for BNs (they would be predicted to show a PPI behavior).

17 The analysis of existential BNs in English is controversial (property-denotation or kinddenotation). Because existential BMNs and B Ps in English have essentially the same properties as the Romance BMNS and BPs (in Romanian, Spanish), it is reasonable to assume the same analysis and to attribute the possibility of kind-reference in English to the presence of a covert Det(erminer) that has the semantics of Chierchia's (1998) Down operator. Romance languages lack such a covert Det and use the definite article for kindreference.

18 The hypothesis that the existential reading of вPs depends on the existential quantifier 
(34) i. $\left[\left[\right.\right.$ citi' $\left.^{\prime}\right]=\lambda P \lambda x \exists y(\operatorname{read}(x, y) \wedge P(y))$

ii. $[[$ romane $]]=\lambda z$ novels $(\mathrm{z})$

iii. $[[$ citi' romane $]]=\left[\left[\right.\right.$ read' $\left.^{\prime}\right]([[$ novels $]])=\lambda x \exists y(\operatorname{read}(\mathrm{x}, \mathrm{y}) \wedge(\lambda \mathrm{z}$ nov$\operatorname{els}(\mathrm{z}))(\mathrm{y}))=$ $=\lambda \mathrm{x} \exists \mathrm{y}(\operatorname{read}(\mathrm{x}, \mathrm{y}) \wedge \operatorname{novels}(\mathrm{y}))$

I-level predicates do not have an existential version:

(35) a. $[[$ intelligent $]]=\lambda x$ intelligent $(x)$

b. $[[$ admire $]]=\lambda x \lambda y(\operatorname{admire}(y, x))$

Such predicates must either be saturated by an entity-type expression or combine with a generalized quantifier. Under the assumption that BNs have a property-type denotation, their incompatibility with these predicates is explained: ${ }^{19}$

(36) Romanian
a. ${ }^{*}$ Copii sunt inteligenţi.
children are intelligent
b. *Admir profesori. admire.1SG professors

\subsection{Predicate Modification}

Another type of semantic composition has been proposed by Dayal (2003) for the analysis of un-Case-marked Hindi Bss and by Dobrovie-Sorin et al. (2005, 2006) and Espinal and McNally (2007, 2011) for Bss in Romanian, Spanish and Catalan. ${ }^{20}$ According to Dobrovie-Sorin et al. (2005, 2006), both B Ps/BMNS and Bss denote properties, but they differ from each other insofar as the former combine with existential predicates (see (34)), whereas the latter rely on

being supplied by the main predicate rather than by the вР itself goes back to Carlson (1977), who combined this idea with the hypothesis of kind-referring в Ps by postulating a realization relation between the kind and an existentially bound variable over realizations of the kind.

19 Because English allows for kind-referring BMNs and B Ps, the counterparts of these examples in English are grammatical. But crucially, the BNs cannot take an existential reading; they can only be interpreted as referring to kinds. 
Dayal's (2003) rule of "semantic pseudo-incorporation"21 shown in $(37)^{22}$ which amounts to saying that they function as modifiers of the main predicate:

(37) $[[\mathrm{V}]]=\lambda \mathrm{P} \lambda \mathrm{y} \exists \mathrm{e}[\mathrm{P}-\mathrm{V}(\mathrm{e}) \wedge \mathrm{Ag}(\mathrm{e})=\mathrm{y} \wedge$ Appropriately Classificatory $(\mathrm{e})]$ where $\exists \mathrm{e} P-\mathrm{V}(\mathrm{e})$ is true iff $\exists \mathrm{e}^{\prime}\left(\mathrm{V}\left(\mathrm{e}^{\prime}\right) \wedge \exists \mathrm{x}\left(\right.\right.$ Theme $\left.\left.\left(\mathrm{e}^{\prime}\right)=\mathrm{x} \wedge \mathrm{P}(\mathrm{x})\right)\right)$ (adapted after Dayal 2011, 146)

(37) represents an "incorporating predicate", which is obtained from a transitive verb of the form $\lambda x \lambda y \lambda e[V(e) \wedge A g(e)=y \wedge T h(e)=x]$, by replacing the Theme argument with a place-holder for a predicate-modifier notated $\mathrm{P}$. The restriction to "appropriately classificatory" events is meant to account for the fact that $\mathrm{V}+$ bare singular sequences must refer to types of events that are culturally stable. Given (37), the object position can be filled by property-denoting nominals, which qualify as predicate-modifiers. Somewhat different implementations of the rule of predicate-modification were proposed by Espinal and McNally (2007, 2011) ${ }^{23}$ and by Chung and Ladusaw (2003).

\subsection{A Unified Semantic Composition for BNS}

Both of the two rules described above apply to property-denoting nominals. This is problematic if we think that one and the same semantic type should compose with the main predicate unambiguously, via the same rule of semantic composition. And we may in fact wonder whether we really need two different rules, one for BSs and one for B PS/BMNS.

A uniform analysis of all BNs is supported by the uniformity of their external syntax (position with respect to the verb, possibility to occur in dislocated positions, etc.). Dobrovie-Sorin and Giurgea (2015, 91-95) showed that both Bss and BPS/BMNs qualify as "pseudo-incorporated" in the sense of Massam (2001).

21 Dayal's (2003) use of the label "pseudo-incorporation" suggests that this semantic rule applies to those Bss that are pseudo-incorporated in Massam's (2001) sense (i.e., VPinternal BNs), as opposed to BSs in the preverbal subject position and to BPs. DobrovieSorin et al. $(2005,2006)$ use the term "Predicate Modification" for Dayal's "pseudo-incorporation".

22 Farkas and De Swart's (2003) rule of Unification of thematic arguments and Chung and Ladusaw's (2003) rule of Restrict are different implementations of the same type of analysis.

23 Espinal and McNally's $(2011,44)$ rule, given below, seems problematic to me because activity verbs such as eat, drink, write allow for implicit roles, that is, they can function as intransitives (John was eating when I arrived) and yet they cannot combine with Bss:

(i) If $[[\mathrm{V}]]=\lambda \mathrm{e}[\mathrm{V}(\mathrm{e})]$ and $\theta$ is an implicit role function defined for $\mathrm{V}$,

and if $[[\mathrm{N}]]=\mathrm{N}$, a property,

then $[[[\mathrm{v} V \mathrm{~N}]]]=\lambda \mathrm{e}[\mathrm{V}(\mathrm{e}) \wedge \mathrm{N}(\theta(\mathrm{e}))]$. 
Thus, all вNs are alike in that they are unable to raise out of their vP-internal position to some IP-internal argument position, which explains why subjects cannot occur in the preverbal position (cf. Martin, Carvalho and Alexiadou, this volume, for Brazilian Portuguese examples where the subject is reinterpreted as an event type). The fact that BNs are not necessarily adjacent to the verb can be attributed to the fact that in Romance, v raises to Infl. All BNs, including Bss, can raise to a left-peripheral position, Topic or Focus.

Regarding internal syntax, Dobrovie-Sorin et al. $(2005,2006)$ argued that BSs were genuinely bare NPS, whereas B Ps had an extra layer of syntactic structure, Num(ber)P. ${ }^{24}$ This will be revised in Section 4.1 below, where I argue that BPs and Bss can be treated alike, as mere projections of little $\mathrm{n}$, that is, as nominal projections that lack both $\mathrm{D}^{\circ}$ and $\mathrm{Num}^{\circ}$.

If indeed all BNs are alike regarding their internal and external syntactic properties, why did certain authors want to treat them differently? The motivation put forth in Dobrovie-Sorin et al. $(2005,2006)$ was the difference in distribution: in certain languages, for example, Romanian, Catalan or Spanish, BSs show a highly restricted distribution: they can only combine with HAVE and with verbs that can be viewed as involving some more abstract notion of possession, such as wear or buy (Espinal and McNally 2007, 2011):25

(38) Romanian

a. Maria $\{$ are / caută/ a cumpărat $\}$ \{maşină / maşini\}. Maria has looks.for has bought car cars 'Maria has / is looking for / bought a car.'

b. Maria $\{$ desenează / vede / aude / vopseşte / mută $\}$ \{maşini / * Maria draws sees hears paints moves cars maşină .

car

'Maria is drawing / sees / hears / is moving cars / *(a) car.'

This more restricted distribution was assumed to be due to the reduced internal structure of Bss: they would be mere NPs, whereas BPs would be (at least) NumPs.

The lack of Num was assumed to explain the "number-neutrality" of Bss (Dobrovie-Sorin et al. 2005, 2006; and especially Espinal and McNally 2007,

24 BMNs were not addressed in Dobrovie-Sorin et al. (2005, 2006).

25 Similarly, un-Case-marked bare NPs have a more restricted distribution than Case-marked bare NPs in Hindi. 
2011). Dobrovie-Sorin and Giurgea (2015, 118-119) observed however that possession verbs, which notoriously allow BSs, also allow B Ps and BMNs:

(39) Romanian

a. Maria are $\{$ cărţi/ ?? carte $\}$. Maria has books book

'Maria has books/ (a) book.'

b. ??Ai mănuşă?

have.2SG glove

b'. Ai mănuşi?

have.2SG gloves

'Are you wearing a glove/gloves?'

Spanish

c. ??El perro tiene oreja larga.

the dog has ear long. SG

c. El perro tiene orejas largas.

the dog has ears long.PL

'The dog has a large ear / large ears.'

Romanian

d. ??Are floare în grădină.

has flowers in garden

d'. Are flori în grădină.

has flowers in garden

'He has a flower / flowers in his garden.'

The choice between BSs and BPs seems to be dictated by whether the conventionalized type of possession involves more than one Possessee of the class $\mathrm{N}$, in which case а вS is not felicitous, and the в Р must be used instead. This observation indicates that Bss are not genuinely number neutral.

Note also that most verbs other than possession verbs refer to episodic events, which by default refer to events that involve more than one participant. Hence the preference for BPs over BSs. BMNS are expected to pattern with BPS, since eventive predicates by default refer to events that involve indeterminate amounts of stuff. 
In sum, the highly restricted distribution of Bss compared to вPs may arguably be explained by invoking pragmatic principles. Provided this can be achieved (which constitutes a research project on its own), all BNs can be analyzed in the same way. And as I observed above, a uniform analysis is supported by the similarity in syntactic properties. Moreover, a uniform semantic composition is supported by the assumption that all BNs are property-denoting expressions.

The question now arises as to which one of the two rules described in Sections 3.1 and 3.2 should be chosen. Because existential quantification over events seems crucial for the analysis of BNs, I will choose Predicate Modification.

In sum:

(40) All BNs (i.e., BSs, BPs and BMNs in subject or object positions) are property-denoting expressions that compose with the main predicate via Predicate Modification.

This proposal does not exclude the possibility that some BNs have other types of denotation, which may be needed for those BNs that seem to behave as strong indefinites. ${ }^{26}$

\subsection{Predicate Modification and Negation}

Going back to obligatory narrow scope with respect to negation, it can be straightforwardly explained: BNs are modifiers of the main verb, they do not contribute any individual variable, and sentential negation involves a negated existential quantifier that binds an event-variable (Acquaviva 1997; Giannakidou 1997 and Zeijlstra 2004).

(41) John didn't buy tickets.

The meaning of (41) would be paraphrased as 'there was no event of John buying tickets'.

26 BPs have been shown to exhibit some properties of strong indefinites in those languages that have "general Number" (Corbett's [2000] terminology), that is, in those languages in which Bss can freely occur in argument positions, in which case they have a "numberneutral" or more precisely an "inclusive plural" interpretation (cf. Kwon and Zribi-Hertz 2004, 2005, for Korean; Bale and Khanjian 2014, for Western Armenian). 


\subsection{Des-indefinites Denote Weak Existential Quantifiers}

According to Dobrovie-Sorin and Beyssade (2012) and Dobrovie-Sorin and Giurgea (2015), BPS and BMNS are full DPs headed by a null $\mathrm{D}^{\circ}$ that denotes an existential Q over sum-entities notated $\emptyset_{\exists}$ :

(42) $\left.\left[{ }_{D} \emptyset_{\exists}\right]\right]=\lambda \mathrm{P}_{\text {cum }} \lambda \mathrm{Q} \lambda \mathrm{e} \exists \mathrm{x}(\mathrm{P}(\mathrm{x}) \wedge \mathrm{Q}(\mathrm{x})(\mathrm{e}))$ defined iff $\exists y, y \neq x$ such that $y=P a r t i c i p a n t(e)$ and $x$ is spatially localized with respect to $\mathrm{y}$ in $\mathrm{e}$

This weak existential determiner should be kept distinct from the strong existential Q (currently analyzed as relying on a choice function), as well as from Chierchia's (1998) Down operator.

The determiner defined in (42) is "selective", in the sense that it is specified to select nominal predicates that are cumulative (notated $\mathrm{P}_{\text {cum }}$ ), that is, either mass or plural NPs. This means that the variable bound by the existential Q does not range over atoms but rather over sums (portions of stuff or pluralities of atoms). This type of existential $Q$ is assumed to be subject to a definedness condition: it is defined only if its second argument (the main predicate) allows for a Participant (argument or adjunct) that is spatially located. ${ }^{27}$

Neither Dobrovie-Sorin and Beyssade (2012) nor Dobrovie-Sorin and Giurgea (2015) were interested in distinguishing between BNs and des-indefinites: Dobrovie-Sorin and Beyssade (2012) assumed that the two types of nominals were alike (existential Qs over sums) and Dobrovie-Sorin and Giurgea (2015) did not discuss des-indefinites.

In order to account for their contrasting behavior with respect to negation, I will assume that BNs lack the $\mathrm{D}^{\circ}$ level of representation (see Section 4.1 below) and correlatively they denote properties and combine with the main predicate via Predicate Modification (as proposed in Section 3.3 above), which explains why they are insensitive to negation (see Section 3.4), ${ }^{28}$ whereas des/de la /du are weak determiners of the semantic type proposed above:

$[[\mathrm{des}]]=\lambda \mathrm{P}_{\text {cum }} \lambda \mathrm{Q} \lambda \mathrm{e} \exists \mathrm{x}(\mathrm{P}(\mathrm{x}) \wedge \mathrm{Q}(\mathrm{x})(\mathrm{e}))$

27 Dobrovie-Sorin and Beyssade (2012) and Dobrovie-Sorin and Giurgea (2015) proposed this type of analysis for existential вPs/BмNs in replacement of property-denotational analyses (see Sections 3.1 and 3.2). An invoked advantage was the assumption that nominals in argument positions be analyzed as having an argument-type denotation (existential Q). Property-type denotation was assumed only for Bss, which were treated as predicate modifiers, with no individual variable filling the argument position.

28 This means that I reject the hypothesis that BNs are headed by null Det's of the type shown in (42) (contra Dobrovie-Sorin and Beyssade 2012 and Dobrovie-Sorin and Giurgea 2015). 
The purpose of this section is to outline syntactic analyses that correlate with the distinct denotations proposed above for BNs and des-indefinites.

\subsection{The Syntax of $\mathrm{BNS}$}

The hypothesis of a unified semantic analysis for BNs proposed in Section 3.3 calls for a unified syntactic analysis. I will therefore reject previous hypotheses according to which BPs differ from BSs in terms of the presence vs absence of the functional category Num(ber). ${ }^{29}$ All BNs will instead be analyzed as nPs. Little $n^{30}$ is particularly relevant for the analysis of в Ps because it can host their plural morphology, thus rendering the projection of Num ${ }^{\circ}$ unnecessary. ${ }^{31}$ BSs themselves can be analyzed not as mere NPs, but rather as nPs headed by a null $\mathrm{n}^{\circ}$. Finally, BMNs would have the same structure as Bss, but would differ from them by the lexical properties of the root. I assume that count roots carry an $\mathrm{AT}(\mathrm{om})$ feature on the root listed in the Lexicon, as opposed to mass roots, which do not have such a feature: ${ }^{32}$

29 Dobrovie-Sorin et al. (2005, 2006) considered BSs as genuinely bare NPs (no functional category) and в Ps as NumPs. They did not take into consideration the lowest functional category in the nominal domain, currently referred to as little $n$. Furthermore, they did not discuss BMNs, which could be taken care of by assuming that they are Measure Phrases (note that $\mathrm{Num}^{\circ}$ itself can be viewed as a particular realization of the functional category Meas ${ }^{\circ}$ for Measure, see Section 4.2 below). This would group together BMNS and BPs, thus correctly capturing their similar distribution across languages.

30 Functional categories such as little $n$ and little $v$ were proposed in Distributed Morphology in order to formalize the difference between syntactic categories and lexical roots. In this framework, there are no NPs or VPs per se, but only nPs and vPs, headed by functional categories (little $\mathrm{n}$ or little $\mathrm{v}$ ) that take roots as complements. Under this view it is roots rather than nouns that are classified as substance or atom-referring. Depending on the language and on the type of DP, little $\mathrm{n}$ was argued to be filled by gender features (Picallo 2005) or by plural features (Lowenstamm 2007; Dobrovie-Sorin 2012).

31 On the hypothesis that plural morphology may realize distinct functional heads see Heycock and Zamparelli (2005).

32 The count vs mass distinction is a highly debated issue. Most theoreticians defend the view that the distinction is purely morphosyntactic, being due to inserting a root that is not distinguished as either "mass" or "count" into the complement of functional heads (Div for Borer 2005 or IND(ividuation) for Bale and Barner 2009), which are responsible for certain Ns behaving as count. Only some authors adopt (some variant of) the hypothesis adopted in the text, according to which roots are classified in the Lexicon as either count or mass (Deal 2017). 
(44) a. zahàr 'sugar' BMN

$\left[\mathrm{n}^{\circ} \emptyset[\right.$ Root zahàr $\left.]\right]$

b. fatà 'girl' BS

$\left[\mathrm{n}^{\circ} \emptyset\right][$ Root-AT fatà $]$

c. fete 'girls' BP

$\left[{ }^{\circ} \mathrm{PL}\right][$ Root-AT fete $]$

Constituents of this type are "bare" in the sense that they lack $\mathrm{D}^{\circ}$, but they do have some reduced functional structure, they are not mere lexical constituents. Such reduced nominal constituents denote properties: (44a) denotes sets of portions of stuff, (44b) sets of atoms and (44c) sets of plural entities. Note that it is not necessary to assume that the syntactic structure of BNs proposed above is the only possible one. Following Ihsane (2008), we may assume that depending on the syntactic context, BPs and BMNs may have structures of different sizes. What counts for explaining their insensitivity to negation is that their underlying syntax may be the minimal possible one, which I take to be $\mathrm{nP}$, the projection of little $n$.

\subsection{The Syntax of des-indefinites}

The morphological form $d e s / d e l a / d u$ is made up of an invariable particle DE followed by PL/FEM/MASc. These forms can, however, clearly be distinguished from the homonymic Prepositional Phrases (P Ps) headed by the preposition de followed by a definite DP (Ihsane 2008; Cardinaletti and Giusti 2017). ${ }^{33}$

I will assume that the $\mathrm{DE}$ inside $\mathrm{des} / \mathrm{de}$ la/du fills the functional head postulated by Schwarzschild (2002) for the analysis of pseudo-partitives. For ease of readability I will use the label Meas ${ }^{\circ}$, introduced by Solt (2009), rather than Schwarzschild's Mon $^{\circ}$. The measure function introduced by $\left[\mathrm{Meas}^{\circ} \mathrm{DE}\right]$ can be interpreted as volume/quantity/weight (of NP), all of which are monotonic, but not as temperature, which is not monotonic.

(45) French

$20 \mathrm{de}$ sucre

20 grams DE sugar

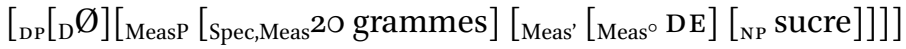

33 Cf. Zamparelli (2008) and Chierchia (1998), who argue that dei-indefinites in Italian are PPS in which the complement DP is kind-referring. 
Given that des/de la/du-indefinites contain DE, I will assume that their syntactic structure is similar to that of pseudo-partitives, modulo the presence of concord gender features (which copy the gender feature value of the $\mathrm{N}$ ) and interpretable number features on $\mathrm{Num}^{\circ} / \mathrm{Meas}^{\circ}$ that check the uninterpretable number features on little n. ${ }^{34}$ I will furthermore assume that $S p e c, M e a s^{\circ}$ is filled with a null element $\emptyset$ with the meaning 'some quantity' or 'some plurality', depending on whether the root is a mass or count $\mathrm{N}$ (see Ihsane, this volume, for a discussion of an implicit quantity in des-N Ps in relation to specificity).

(46) French

a. $d u \quad$ sucre

PA.M.SG sugar

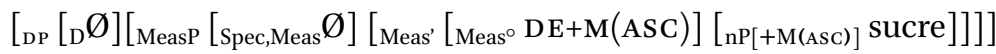

b. de la farine

PA F.SG flour

${ }_{\mathrm{DP}}\left[{ }_{\mathrm{D}} \emptyset\right]\left[\left[_{\text {MeasP }}[\right.\right.$ spec,Meas $\emptyset]\left[\right.$ Meas' $^{\prime}$ Meas $\left.^{\circ} \mathrm{DE}+\mathrm{F}(\mathrm{EM})\right]\left[{ }_{\mathrm{nP}[+\mathrm{F}(\mathrm{EM})]}\right.$ farine $\left.\left.\left.]\right]\right]\right]$

c. des garçons

PA.PL boys

${ }_{\mathrm{DP}}\left[{ }_{\mathrm{D}} \emptyset\right]\left[\right.$ MeasP $\left._{\text {Spec,Meas }} \emptyset+\mathrm{PL}\right]\left[\right.$ Meas' $\left[\right.$ Meas $\left.^{\circ} \mathrm{DE}+\mathrm{PL}\right]\left[{ }_{\mathrm{nP}[+\mathrm{PL}]}\right.$ garçons $\left.\left.]\right]\right]$

Given the presence of MeasP and $\mathrm{D}^{\circ}$, des-indefinites cannot be assumed to denote mere properties but must have an argument-type denotation. And since in unmarked contexts, des-indefinites function as weak indefinites, I will assume that Dobrovie-Sorin and Giurgea's (2015) weak existential Q takes MeasP as a complement:

(47) $\left[{ }_{D} \emptyset_{\exists}\right][$ Measp $\operatorname{des}$ étudiants $]=\lambda \mathrm{Q} \lambda \mathrm{e} \exists \mathrm{x}\left({ }^{*} \operatorname{student}(\mathrm{x}) \wedge \mathrm{Q}(\mathrm{x})(\mathrm{e})\right)$, defined iff $\exists y, y \neq x$ such that $y=P a r t i c i p a n t(e)$ and $x$ is spatially localized with respect to $\mathrm{y}$ in $\mathrm{e}$

34 This is in line with Heycock and Zamparelli (2005), who assume that plural features can be inserted in more than one syntactic position, in our case both in Num ${ }^{\circ} / \mathrm{Meas}^{\circ}$ and little $n$. However, the suggestion made in the text here is somewhat different, because plural features are not only allowed to choose between two positions but also to occur in more than one position inside the same DP. I will not pursue the theoretical implications of this proposal here. 
This configuration satisfies the selectional restriction mentioned in Section 3.5, which constrains the weak existential determiner to apply to a cumulative predicate: indeed, MeasP constituents denote cumulative predicates, sets of sums of atoms or sets of sums of amounts of stuff.

\section{Weak Existential Quantifiers and Negation}

In this section I will propose a line of explanation for the alternation between the inflected forms des, de la, du found in affirmative contexts and the invariable $d e$ found in negative contexts:

(48) French

Jean a lu des livres.

Jean has read PA.PL books

'Jean read some books.'

(49) French

Jean n' a pas lu de livres.

Jean NEG has not read DE books

'Jean didn't read any book.'

The invariable de will be analyzed as a strict NPI, and I will assume Collins and Postal's (2014) analysis of strict NPIS.

We will then turn to des-indefinites, which are clearly neither NPIs nor $\mathrm{N}$ (egative)-words. In order to explain the unavailability of their narrow scope with respect to negation, I will make two assumptions: (i) a sentence with multiple negations that is interpreted as involving just one negation is to be analyzed as involving polyadic negative quantification; (ii) polyadic quantification is syntactically constrained by Determiner Sharing (Collins and Postal 2014).

\subsection{Collins and Postal's (2014) Analysis of NPIs Applied to Invariable de}

Because the French indefinites headed by the invariable de are allowed to scope under negation, they qualify as NPIs. They are strict NPIS ${ }^{35}$ because, in contrast to any in English, de-indefinites are not allowed in downward

35 Starting with Horn (1971), theoreticians agree that different classes of NPIs need to be distinguished (see Van der Wouden 1997, for an overview), but they do not agree on the classification. For our present purposes it is sufficient to assume that a strict NPI can only 
entailing contexts such as restrictors of universal quantifiers, questions, etc., as in for example Chaque étudiant qui a lu des/*de livres de linguistique "Each student who has read linguistics books', As-tu lu des/*de livres? 'Have you read books?' This means that the NPI behavior of $d e$-indefinites cannot be explained as being due to semantic operations such as domain widening and strengthening (Kadmon and Landman 1993) or exhaustification (Chierchia 2006, 2013).

I will instead use Collins and Postal's (2014) analysis (based on Klima 1964) according to which NPIs, any in particular, are generated as negative existential determiners. Thus, the any in the $\mathrm{b}$ example below has exactly the same underlying structure as no: ${ }^{36}$

(50) a. I saw no widow.

b. I didn't see any widow.

(51) a. any: [D NEG [SOME]]

b. no: $\left[{ }_{D} \mathrm{NEG}[\mathrm{SOME}]\right]$

Collins and Postal treat DPs headed by any not as indefinites (as currently assumed since Ladusaw 1979) but rather as negative quantificational DPs of the form [ $\left.{ }_{D} \mathrm{NEG}[\mathrm{SOME}] \mathrm{NP}\right]$, underlyingly indistinguishable from negative quantificational DPs headed by no.

Granting the underlying identity between [no NP] and [any NP], the surface forms of sentences containing any are obtained by assuming a syntactic operation, namely (i) NEG raising out of the DP and two morphophonological rules: (ii) the raised NEG is phonologically realized as not, and (iii) SOME is realized as any. Striking out (my notation) indicates a deleted copy (under the copy-theory of movement):

(52) I did [ $\left.{ }_{\mathrm{NEG}} \mathrm{not}\right]$ see $\left[\mathrm{DP}_{\mathrm{D}}\left[\mathrm{D}_{\mathrm{NEG}} \mathrm{not}\right]\left[\right.\right.$ some $_{\text {sony }}$ and widow $]$.

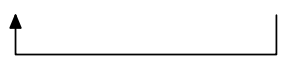

be legitimated by an antiadditive function (e.g., negation or the preposition without) in a local context.

36 According to Collins and Postal (2014), the any in (5ob) is a strict NPI, which needs to be distinguished from the any that is legitimated in downward entailing non-negative contexts, which Collins and Postal analyze as containing two negative operators [ ${ }_{D}$ NEG [NEG [SOME]]], instead of just one. 
The notation [ $\left[_{\mathrm{NEG}}\right.$ not] [ some any $\left.]\right]$ is also mine. It is meant to represent in a concise way Collins and Postal's assumption that the NEG and SOME that underlyingly make up any are respectively realized as not and as any.

Collins and Postal's analysis of any can be easily extended to cover the French $d e$-indefinites legitimated by pas, a case which is not considered by the authors:

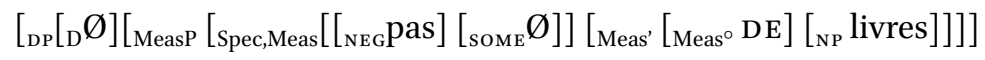

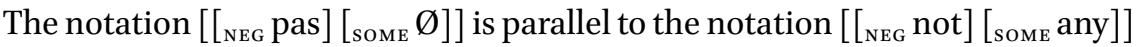
used above: the NEG and SOME that underlie the invariable de in French are respectively realized as pas and a null element. Further details of the representation in (53) such as the Meas head and its projection have been motivated in Section 4 above. The DP-internal position of pas is motivated by the fact that in fragment answers pas immediately precedes the de NP constituent, as in, Q: Qu'est-ce que tu désires comme cadeau? 'What would you like as a gift?'; A: Pas de livres 'Not books'.

Kayne (1975, his Section 2.5) suggested that indefinites introduced by invariable DE in negative sentences are to be analyzed as nominals of the form [Ø de $\mathrm{NP}]$, where $\emptyset$ is an empty QP. Kayne's analysis neatly correlates with the structure given above, in which [[ NEG $_{\text {pas }}$ [some $\left.\varnothing\right]$ ] sits in Spec,Meas, the dedicated position for QPS. Note that neither Kayne (1975) nor Kayne (1984, chapter 4) assume that pas is inserted inside the DP in the relevant underlying representation; nevertheless, Kayne (1984) proposed that pas can serve as the antecedent of the $\emptyset$ inside the $d e$-nominal. Since any minimalist implementation of this proposal involves movement (Second Merge), it seems safe to say that the proposal made here constitutes on the one hand an updated version of Kayne's $(1975,1994)$ analysis of $d e$-indefinites under the scope of $p^{2} s^{37}$ and on the other hand a refinement suggested by Collins and Postal's analysis of strict NPIs.

The underlying syntax of the example in (49) would thus be (54):

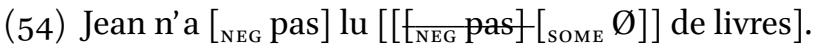

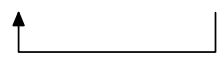

The reader should be aware of the fact that not all French $d e$-indefinites are obtained from the structure shown in (54), which means that not all de-indefinites are NPIs. Indeed, bare de indefinites can be derived by moving beaucoup 'many, much', peu 'little, few' or combien 'how much' out of the DP, thus yielding the so-called "Quantification at a Distance" configuration (Kayne 1975, 1984; Obenauer 1994; Honcoop 1992; De Swart 1992; Doetjes 1994; Doetjes and Honcoop 1997): 
Given that $\left[\left[\left[_{\mathrm{NEG}}\right.\right.\right.$ pas $\left.]\left[{ }_{\text {somE }} \emptyset\right]\right]$ translates as a negative existential quantifier, the corresponding LF would involve a unary negative quantifier $\neg \exists$ that binds an individual variable:

(55) $\neg \exists_{\mathrm{z}}\left({ }^{*} \operatorname{book}(\mathrm{z}) \wedge\right.$ John read $\left.\mathrm{z}\right)$

\subsection{Polyadic Quantification}

Let us now consider the unacceptable examples in which a des-indefinite needs to be interpreted under the scope of sentential negation, but cannot do so:

\section{(56) French}

*Jean n' a pas lu des livres.

Jean NEG has not read PA.PL books

Part of the explanation of this unacceptability is trivial: des-indefinites are not NP Is, which means that their underlying structure does not contain any negative element, and therefore, the example in (56) cannot be derived by raising NEG from inside the DP.

This is however not the end of the story. We must indeed also rule out the following alternative derivation: pas is first merged as a NEG modifier of $\mathrm{V}$ or VP and des stays in its DP-internal position.

My account will build on the following assumption, which crucially relies on the notion of polyadic quantification:

(57) (In unmarked contexts) ${ }^{38}$ local narrow scope with respect to negation (i.e., with respect to a negated main predicate) is read off an LF relying on polyadic quantification in which a unique negative existential $\neg \exists$

(i) J'ai lu beaucoup de livres.

I=have read many of books.

'I've read many books.'

(ii) J'ai beaucoup lu de livres.

I=have many read of books.

'I've read many books.'

The fact that $d e$-indefinites are ambiguous between strict N P Is and "remnants" of Quantification at a distance is an interesting fact, which as far as I know has not been yet examined within existing theories of NPIS.

38 The restriction to unmarked contexts is meant to leave aside the examples discussed in Sections 2.2 and 2.3. Such "exceptional" examples would not be analyzable as involving negative existential quantification over events, that is, as denying the existence of events, but rather as denying propositions. 
binds an n-tuple that contains one event-variable and one or more individual variables.

Polyadic (also called "n-ary") quantification is a configuration in which a single quantifier ${ }^{39}$ binds an n-tuple of variables (Keenan 1987; May 1989). Polyadic quantification is particularly appropriate for the analysis of Negative Concord (De Swart 1999; De Swart and Sag 2002). Indeed, in negative concord environments, two co-occurring negatively marked DPs (N-words) yield a single negation:

\section{(58) Romanian}

Niciun student $n$-a citit nicio carte. no student not-has read no book 'No student read any book.'

The single negation interpretation of such sentences cannot be obtained by assuming that each of the $\mathrm{N}$-words counts as a negative quantifier. If that were the case the two negations would cancel each other, yielding a meaning identical to that of (59b), which does not correspond to the interpretation of negative concord sentences:

(59) a. $\neg \exists_{\mathrm{x}}: \operatorname{student}(\mathrm{x}) \cdot \neg \exists_{\mathrm{y}}: \operatorname{book}(\mathrm{y}) \cdot \mathrm{x} \operatorname{read} \mathrm{y}$

b. $\forall_{\mathrm{x}}: \operatorname{student}(\mathrm{x}) \cdot \exists_{\mathrm{y}}$ : $\operatorname{book}(\mathrm{y}) \cdot \mathrm{x} \operatorname{read} \mathrm{y}$

The observable single negation reading can be captured by using polyadic quantification, which allows several variables to be bound by the same negative quantifier:

(6o) $\neg \exists_{\langle x, y)}: \operatorname{student}(\mathrm{x}), \operatorname{book}(\mathrm{y}) \cdot \mathrm{x}$ read y

Collins and Postal (2014) contribute two novel ingredients to the theory of negative polyadic quantification. On the one hand, they use polyadic quantification not only for the analysis of negative sentences containing N-words, but also for those containing one or more NPIs in addition to an N-word.

39 Note that "single" quantifier does not mean a "non-complex" quantifier. The notion of polyadic/non-unary quantifier also applies to sequences of quantifiers, see in particular Keenan (1987), who uses the binary quantifier [each, different] for examples of the type Each student read a different book. 
This extension is entailed by Collins and Postal's analysis of NPIs (see the previous subsection): since under their theory NPIs are underlyingly negative existential quantifiers, they will yield the same type of LF analysis as N-words. On the other hand, Collins and Postal $(2014,51)$ propose that polyadic quantification is syntactically conditioned by Determiner Sharing:

(61) "The syntactic basis of polyadic quantification structures [...] involves syntactic determiner sharing between the different DPs [...]."

Determiner Sharing is transparent in negative concord configurations, which are built with several N-words, each of which is underlyingly a [NEG SOME] constituent. Thus, the example in (58) can be represented as in (62), where the indices notate sharing:

(62) $\left[\mathrm{NEG}_{\mathrm{e}} \mathrm{SOME}_{\mathrm{f}}\right]_{\mathrm{a}}$ student read $\left[\mathrm{NEG}_{\mathrm{e}} \mathrm{SOME} \mathrm{f}_{\mathrm{a}}\right.$ book

In its minimalist implementation, the notion of "syntactic determiner sharing" involves First Merge ${ }^{40}$ of the same determiner, in this case [NEG SOME], into more than one syntactic position (see Collins and Postal 2014, 51-53).

Although Collins and Postal do not provide explicit analyses of examples with polyadic quantification in which one of the negative elements is first merged on the VP (and correlatively they do not make use of event-variables in their analyses), their theory can be extended to such cases. In particular, their notion of "Determiner" covers negative quantifiers that are first merged not only DP-internally, but also as VP modifiers.

Let us now go back to our problem, the obligatory use of de instead of des in the local scope of a negation, in particular in the local scope of sentential negation. In Section 5.1 I have sketched an analysis of $d e$-indefinites based on Collins and Postal's analysis of NPIs. Here, I will analyze the same example under the following alternative derivation:

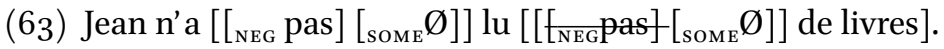

40 Collins and Postal make it clear that Determiner Sharing does not arise via movement (Second Merge). The reason is obvious: polyadic quantification corresponds to syntactic configurations in which two or more negations are independently merged, not to two or more copies of a unique negation. 
This configuration involves Determiner Sharing, since [NEG SOME] is First merged both VP- and DP-internally. ${ }^{41}$ First merge of pas on the VP is independently needed for those examples that contain no negative DP, but only sentential negation, as for example Jean n'est pas venu 'John hasn't come'. The lack of morphophonological realization for the DP-internal [ ${ }_{\mathrm{NEG}}$ pas] is in this case due to deletion under identity with the higher [NEG $_{\mathrm{NG}}$ pas], an operation that Collins and Postal independently assume for examples like No man loves any woman.

Given the Determiner Sharing syntactic configuration in (63), polyadic quantification obtains at $\mathrm{LF}$, in which a unique negative existential quantifier binds a tuple that contains an event variable (corresponding to the negative quantifier attached to the VP) and an individual variable corresponding to the negative-marked DP:

(64) $\neg \exists_{\langle\mathrm{e}, \mathrm{z}\rangle}\left({ }^{*} \operatorname{book}(\mathrm{z}) \wedge \operatorname{read}(\mathrm{e}) \wedge\right.$ Theme $(\mathrm{e})=\mathrm{z} \wedge$ Agent $(\mathrm{e})=$ Jean $)$

Turning now to the unacceptability of des-indefinites in negative contexts (see (56)), it can be explained as being due to the fact that Determiner Sharing does not obtain, because this example is built with two different Determiners, [NEG SOME] on the VP, and [SOME] inside the DP. In the absence of Determiner Sharing polyadic quantification does not obtain at LF.

In order to rule out the relevant interpretation we need the requirement for polyadic quantification stated in (57): the so-called "local narrow scope with respect to negation" cannot be obtained via a scoping mechanism (which would simply place the positive existential in the scope of the negative existential), but only via polyadic quantification.

Let us finally briefly go back to the example in (48), which arguably also involves polyadic quantification. In this example, the same underlying determiner [SOME] can be assumed to be merged in two distinct positions, on the one hand inside the DP (where it is realized as des), and on the other hand in a VP adjunction position (where it would remain silent). Given that the syntactic configuration relies on Determiner Sharing and given that SOME translates as the existential $\exists$, an LF relying on polyadic quantification can be assigned, in which a unique existential quantifier binds a pair of event and individual variable:

41 This is different from the derivation proposed in Section 5.1, which involved only one [NEG SOME], first merged inside the DP and raised from there to some VP-adjunction position. 
(65) $\exists\langle\mathrm{e}, \mathrm{z}\rangle\left({ }^{*} \operatorname{book}(\mathrm{z}) \wedge \operatorname{read}(\mathrm{e}) \wedge\right.$ Theme $(\mathrm{e})=\mathrm{z} \wedge$ Agent $(\mathrm{e})=$ Jean $)$

In sum, if we assume Collins and Postal's (2014) syntax-based analysis of polyadic quantification, sentences that contain des in the local domain of negation cannot yield polyadic quantification at LF. And granting that the intended meaning (in which the indefinite does not scope out) can only be represented as involving polyadic quantification, examples of this type are correctly ruled out.

In this paper I have proposed an explanation of the alternation between des/de $l a / d u$ in positive sentences vs invariable $d e$ in negative sentences. In intuitive terms, the central idea is that nominals introduced by des/de la/du sitting in argument positions denote weak existential Qs, and this denotation is incompatible with a negated existential Q over events. For the technical implementation I relied on Collins and Postal's (2014) principle of Determiner Sharing, which according to these authors is the "syntactic basis" of negative polyadic quantification. In a nutshell, scope under sentential negation can only be read off polyadic quantificational LF, and this requires Determiner Sharing in the syntax. Des-indefinites and sentential negation do not satisfy Determiner Sharing, hence the ban on des-indefinites under sentential negation. Indefinites headed by the invariable $d e$, on the other hand, are to be analyzed as involving a raised or deleted negation (pas), which explains why de-indefinites take narrow scope with respect to sentential negation.

In sum, we have been able to explain the PPI status of weak indefinites, which arguably have no scalar properties. Such PPIs are sensitive to antiadditive operators, but not to other downward entailing operators.

The proposal has the following consequences: (i) des-indefinites in argument positions and BNs in argument positions have distinct denotations; (ii) all BNS (BSs, but also BPs and BMNs) denote properties. This means that the highly restricted distribution of BSs (compared to BPS and BMNs) must be attributed to pragmatic principles that take into account the lexical meaning of the main predicate and conventionalized meanings of singular vs plural markings; (iii) des-indefinites in predicate positions (as well des-indefinites that do not occur in argument positions at LF) are property-denoting. 


\section{Acknowledgments}

I would like to thank the organizers of the workshop "Bare nouns vs. 'partitive articles': disentangling functions" at the 5oth Annual Meeting of the Societas Linguistica Europaea in Zürich in September 2017, Tabea Ihsane and Elisabeth Stark, for having invited me to think again about an old obsession of mine, the (dis)similarities between des-indefinites and bare nominals. And then this got me into the world of negation, which I had never dared approach before. The research reported here is my first attempt to make sense of the PPI status of weak indefinites, in particular des-indefinites. I would also like to thank Sasha Simonenko for having accepted to join me (at least temporarily, see our joint abstract and h-out for IGG 2019) in this enterprise. I do hope that some time in the near future we will continue working together on the numerous issues left open here. I also benefitted from presenting this work in the Labex-PLU seminar and thank the participants, in particular Lucia Tovena, for their comments. Most helpful were the requests formulated by the external reviewer of this volume. I am grateful for the work this severe but well-intended reviewer, together with Keir Moulton and Tabea Ihsane, put into reading this article. Special thanks go to Tabea Ihsane for her extremely careful reading of this article (in its various versions), her numerous helpful comments on the content and also for the tedious but so precious editorial work. All errors are mine, and note that there may be some, since this final version has been considerably enriched compared to the previous ones.

\section{References}

Acquaviva, Paolo. 1997. The logical form of negation. New York: Garland.

Attal, Pierre. 1976. "A propos de l'indéfini des. Problèmes de representation sémantique." Le Français Moderne 44, no. 2: 126-142.

Bale, Alan C., and David Barner. 20og. "The interpretation of functional heads: Using comparatives to explore the mass/count distinction." Journal of Semantics 26, 217252. doi:10.1093/jos/ffpoo3.

Bale, Alan C., and Hrayr Khanjian. 2014. "Syntactic complexity and competition: The singular-plural distinction in Western Armenian." Linguistic Inquiry 45, no. 1: 1-26. http://hdl.handle.net $/ 1721.1 / 87585$.

Borer, Hagit. 2005. In Name Only. Structuring Sense, vol. 1. Oxford: Oxford University Press.

Bosveld-de Smet, Leonie. 1998. On mass and plural quantification: The case of French des/du-NPS. PhD Diss., Institute for Logic, Language and Computation, Universiteit van Amsterdam. 
Bosveld-de Smet, Leonie. 2004. "Towards a uniform characterization of noun phrases with des or du." In Handbook of French Semantics, edited by Francis Corblin and Henriëtte De Swart, 41-54. Stanford, CA: CSLI Publications.

Cardinaletti, Anna, and Giuliana Giusti. 2017. "Quantified expressions and quantitative clitics." In The Wiley Blackwell Companion to Syntax 2nd ed., edited by Martin Everaert and Henk C. Van Riemsdijk, 1-42. Oxford: Wiley. doi:10.10o2/9781118358733.wbs yncomo63.

Carlson, Greg N. 1977. "A unified analysis of the English bare plural." Linguistics and philosophy 1, no. 3: 413-457. https://doi.org/10.1007/BFoo353456.

Chierchia, Gennaro. 1998. "Reference to kinds across language." Natural language semantics 6, no. 4: 339-405. https://doi.org/10.1023/A:10o8324218506.

Chierchia, Gennaro. 2006. "Broaden your views: Implicatures of domain widening and the logicality of language." Linguistic inquiry 37, no. 4: 535-59o. https://doi.org/10 $.1162 /$ ling.2006.37.4.535

Chierchia, Gennaro. 2013. Logic in grammar. Polarity, Free Choice and intervention. Oxford: Oxford University Press.

Chung, Sandra, and William A. Ladusaw. 2003. Restriction and saturation. Cambridge, MA: MIT Press.

Corbett, Greville G. 200o. Number. Cambridge: Cambridge University Press.

Corblin, Francis. 2001. "Où situer certains dans une typologie sémantique des groupes nominaux?” In Typologie des groupes nominaux, edited by Georges Kleiber, Brenda Laca and Liliane Tasmowski, 47-99. Rennes: Presses Universitaires de Rennes.

Corblin, Francis, and Henriëtte De Swart, eds. 2004. Handbook of French semantics. Stanford, CA: CSLI publications.

Collins, Chris, and Paul M. Postal. 2014. Classical NEG raising: An essay on the syntax of negation, vol. 67. Cambridge, MA: MIT press.

Dayal, Veneeta. 2003. "A semantics for pseudo-incorporation.” Ms., Rutgers University.

Dayal, Veneeta. 2011. "Hindi pseudo-incorporation." Natural Language and Linguistic Theory 29, no. 1: 123-167. https://doi.org/10.1007/s11049-011-9118-4.

Deal, Amy Rose. 2017. "Countability distinctions and semantic variation." Natural Language Semantics 25: 125-171. https://doi.org/10.1007/s11050-017-9132-o.

De Swart, Henriëtte. 1992. "Intervention effects, monotonicity and scope." Semantics and Linguistic Theory, vol. 2: 387-406.

De Swart, Henriëtte. 1999. "Negation and negative concord in a polyadic quantification framework." Accessed June 8, 2020, http://festschriften.illc.uva.nl/j5o/contribs/ deswart/index.html.

De Swart, Henriëtte, and Ivan A. Sag. 2002. "Negation and negative concord in Romance." Linguistics and Philosophy 25: 373-417. https://doi.org/10.1023/A:1020823106 639.

Diesing, Molly. 1992. Indefinites. Cambridge, MA: MIT Press. 
Dobrovie-Sorin, Carmen. 1997. "Types of predicates and the representation of existential readings." In Proceedings of SALT VII, edited by Aaron Lawson (Stanford, April 1997), 117-134. New-York: Cornell University Press. http://dx.doi.org/10.3765/salt.v7io .2796 .

Dobrovie-Sorin, Carmen. 2012. "Number as a feature." In Functional heads, edited by Laura Brugé et al., 304-324. Oxford: Oxford University Press.

Dobrovie-Sorin, Carmen, and Claire Beyssade. 2004. Définir les indéfinis. Paris: CNRS Editions.

Dobrovie-Sorin, Carmen, and Claire Beyssade. 2012. Redefining indefinites. Dordrecht: Springer.

Dobrovie-Sorin, Carmen, Tonia Bleam, and Maria Teresa Espinal. 2005. "Noms nus, nombre et types d'incorporation". In Noms nus et généricité, edited by Carmen Dobrovie-Sorin et al., 129-157. Paris: PU Vincennes.

Dobrovie-Sorin, Carmen, Tonia Bleam, and Maria-Teresa Espinal. 20o6. "Bare nouns, number and types of incorporation." In Non-definiteness and plurality, edited by Liliane Tasmowski and Svetlana Vogeleer, 51-79. Amsterdam: John Benjamins.

Dobrovie-Sorin, Carmen, and Ion Giurgea. 2015. "Weak Reference and Property Denotation. Two types of Pseudo-Incorporated Bare Nominals." In The Syntax and Semantics of Pseudo-Incorporation, edited by Olga Borik and Berit Gehkre Leiden, 88-125. Boston: Brill.

Dobrovie-Sorin, Carmen, and Brenda Laca. 2003. "Les noms sans déterminant dans les langues romanes." In Les langues romanes. Problèmes de la phrase simple, edited by Danièle Godard, 235-281. Paris: CNRs Editions.

Doetjes, Jenny. 1994. "Quantification at a distance and event relatedness." Linguistics in the Netherlands 11, no. 1: 13-24.

Doetjes, Jenny, and Martin Honcoop. 1997. "The Semantics of Event-Related Readings: A Case for Pair-Quantification." In Ways of Scope Taking. Studies in Linguistics and Philosophy, edited by Anna Szabolcsi, vol. 65. Dordrecht: Springer. https://doi.org/10 .1007/978-94-011-5814-5_8.

Dryer, Matthew S. 1996. "Focus, pragmatic presupposition and activated propositions." Journal of Pragmatics 26: 475-523. https://doi.org/10.1016/o378-2166(95)ooo59-3.

Espinal, Maria-Teresa, and Louise McNally. 2007. "Bare singular nominals and incorporating verbs." In Proceedings of the III NERE Us International Workshop. Definiteness, Specificity and Animacy in Ibero-Romance languages, edited by Georg Kaiser and Manuel Leonetti, 45-62 (Arbeitspapier 122). Konstanz: Universität Konstanz.

Espinal, Maria-Teresa, and Louise McNally. 2011. "Bare singular nouns and incorporating verbs in Spanish and Catalan." Journal of Linguistics 47: 87-128.

Fălăuş, Anamaria. 2018. "Positive polarity indefinites? On how (not) to identify them: An exhaustification-based perspective." Linguistics 56, no. 2: 301-331.

Farkas, Donka, and Henriëtte De Swart. 2003. The semantics of incorporation: From argument structure to discourse transparency. Stanford, CA: CSLI Publications. 
Galmiche, Michel. 1986. "Note sur les noms de masse et le partitif." Langue française 72: 40-53. https://doi.org/10.3406/lfr.1986.4657.

Garzonio, Jacopo, and Cecilia Poletto. 2020. "Partitive objects in negative contexts in Northern Italian Dialects.” In Shades of Partitivity: formal and areal properties, edited by Tabea Ihsane and Elisabeth Stark. Special Issue in Linguistics.

Giannakidou, Anastasia. 1997. The landscape of polarity items. PhD Diss., Rijksuniversiteit.

Giannakidou, Anastasia. 1998. Polarity Sensitivity as (Non)veridical Dependency. Amsterdam, Philadelphia: John Benjamins.

Giannakidou, Anastasia. 200o. "Negative ... Concord?" Natural Language and Linguistic Theory 18: 457-523.

Giannakidou, Anastasia. 2011. "Positive polarity items and negative polarity items: variation, licensing, and compositionality." In Semantics: An International Handbook of Natural Language Meaning (Second edition), edited by Claudia Maienborn, Klaus Von Heusinger, and Paul Portner, 166o-1712. Berlin: de Gruyter.

Giusti, Giuliana. This volume. "A Protocol for Indefinite Determiners in Italian and Italo-Romance."

Gross, Maurice. 1967. "Sur une règle de 'cacophonie'." Langages (Linguistique française. Théories grammaticales) 2, no. 7: 105-119. https://doi.org/10.3406/lgge.1967.2886.

Heycock, Caroline, and Roberto Zamparelli. 2005. "Friends and colleagues: Plurality, coordination, and the structure of DP." Natural language semantics 13, no. 3: 201270. https://doi.org/10.1007/s11050-004-2442-z.

Homer, Vincent. 2011. Polarity and modality. PhD Diss., University of California, Los Angeles.

Honcoop, Martin. 1992. “ER or OR: Quantification, intervention and fission.” Master's thesis, University of Leiden.

Doetjes, Jenny, and Martin Honcoop. 1997. "The semantics of event-related readings: A case for pair-quantification." In Ways of scope taking, edited by Anna Szabolcsi, 263-310. Dordrecht: Springer.

Horn, Laurence. 1989. A natural history of negation. Chicago: University of Chicago Press.

Ihsane, Tabea. 2008. The layered DP: Form and meaning of French indefinites. Amsterdam, Philadelphia: John Benjamins.

Ihsane, Tabea. This volume. "Telicity, Specificity, and Complements with a 'Partitive Article' in French."

Jespersen, Otto. 1917. Negation in English and other languages. Copenhagen: A.F. Host. Kadmon, Nirit, and Fred Landman. 1993. "Any." Linguistics and Philosophie 26, no. 4: 353-422. www.jstor.org/stable/25001516.

Kayne, Richard. 1975. French Syntax: The Transformational Cycle. Cambridge, MA: MIT Press. 
Kayne, Richard. 1984. Connectedness and binary branching. Dordrecht: Foris.

Keenan, Edward L. 1987. “Unreducible n-ary quantifiers in natural language." In Generalized quantifiers, edited by Peter Gärdenfors, 109-150. Dordrecht: Reidel.

Kleiber, George. 1989. "L' opposition massif/comptable et les adjectifs." In Termes massifs et termes comptables, edited by Georges Kleiber and Jean David, 267-292. Paris: Klincksieck.

Kleiber, Georges. 2001. "Lecture existentielle et lecture partitive." In Typologie des groupes nominaux, edited by Georges Kleiber, Brenda Laca and Liliane Tasmowski, 47-99. Rennes: Presses Universitaires de Rennes.

Klima, Edward. 1964. "Negation in English." In The structure of language, edited by Jerry A. Fodor and Jerrold J. Katz, 246-323. Englewood Cliffs, nJ: Prentice Hall.

Kupferman, Lucien. 1979. “L' article partitif existe-t-il?" Le français moderne 47: 1-16.

Kwon, Song-Nim, and Anne Zribi-Hertz. 2004. "Number from a syntactic perspective: why plural marking looks 'truer' in French than in Korean." Empirical issues in syntax and semantics 5: 133-158.

Kwon, Song-Nim, and Anne Zribi-Hertz. 2005. "Pluriel et généricité nominale: les enseignements du coréen." In Noms nus et généricité, edited by Carmen DobrovieSorin et al., 159-196. Paris: PU Vincennes.

Laca, Brenda. 1990. “Generic objects: some more pieces of the puzzle." Lingua 81, no. 1: 25-46. https://doi.org/10.1016/0024-3841(9o)900o3-4.

Ladusaw, William A. 1979. Polarity sensitivity as inherent scope relations. PhD Diss., University of Texas. Published, 1980, New York: Garland.

Larrivée, Pierre. 2012. "Positive polarity items, negation, activated propositions." Linguistics 5o, no. 4: 869-900. DoI: 10.1515/ling-2012-0027.

Le Bruyn, Bert. 2010. Indefinite Articles and Beyond. Netherlands: LOT.

Lowenstamm, Jean. 2007. "On Little n, rоoт, and Types of Nouns." In The Sounds of Silence: Empty Elements in Syntax and Phonology, edited by Jutta Hartmann, Veronika Hegedus and Henk Van Riemsdjik, 105-143. Amsterdam: Elsevier.

Martin, Fabienne, Janayna Carvalho, and Artemis Alexiadou. This volume. "Predicates of Personal Taste and Pancake Sentences in Brazilian Portuguese and French.”

Massam, Diane. 2001. "Pseudo Noun Incorporation in Niuean." Natural Language and Linguistic Theory 19, no. 1: 153-197. https://doi.org/10.1023/A:10o6465130442.

McNally, Louise. 1995. "Bare plurals in Spanish are interpreted as properties." In Proceedings of the 1995 CSSLLI Conference on Formal Grammar, edited by Glyn Morrill and Richard Oerhle, 197-212. Republished in 2004, Catalan Journal of Linguistics 3 , $115^{-133 .}$

McNally, Louise. 1998a. "Existential sentences without existential quantification." Linguistics and Philosophy 21: 353-392.

McNally, Louise. 1998b. "Stativity and theticity." In Events and Grammar, edited by Susan Rothstein, 293-307. Dordrecht: Kluwer. 
May, Robert. 1989. "Interpreting logical form." Linguistics and Philosophy 12: 387-435.

Milsark, Gary. 1977. "Peculiarities of the existential construction in English." Linguistic Analysis 3: 1-29.

Nicolae, Andreea. 2012. "Positive polarity items: an alternative-based account." Proceedings of Sinn und Bedeutung 16, no. 2: 475-488. Accessed April 9, 2020, https://ojs.ub .uni-konstanz.de/sub/index.php/sub/article/view/441.

Nicolae, Andreea C. 2017. "Deriving the positive polarity behavior of plain disjunction." Semantics and Pragmatics 10, no. 5: 1-21. http://dx.doi.org/10.3765/sp.10.5.

Obenauer Hans-Georg. 1994. Aspects de la syntaxe A-barre. PhD Diss., Université de Paris VIII.

Picallo, Carmen. 2005. "Some Notes on Grammatical Gender and l-Pronouns." In Proceedings of the Workshop Specificity and the Evolution/Emergence of Nominal Determination Systems in Romance, edited by Klaus Von Heusinger, 107-121 (Arbeitspapier 119). Universität Konstanz: Fachbereich Sprachwissenschaft.

Progovac, Ljiljana. 200o. "Negative and Positive Feature Checking and the Distribution of Polarity Items." In Negation in Slavic, edited by Sue Brown and Adam Przepiorkowski, 179-217. Bloomington, IN: Slavica Publishers.

Roodenburg, Jasper. 2004. "French bare arguments are not extinct: The case of coordinated bare nouns." Linguistic Inquiry 35, no. 2: 301-313. doi: 10.1162/oo2438904323019 o93.

Schurr, Hagay. This volume. "Bound To Be? Bare and Partitive-Marked Noun Phrases in Romance Languages and the Emergence of Prominence-Conditioned Patterns."

Schwarzschild, Roger. 2002. "The grammar of measurement." In Proceedings of the 12th Semantics and Linguistic Theory Conference (SALT), edited by Brendan Jackson, 225245. Ithaca, NY: CLC Publications.

Simonenko, Alexandra, and Dobrovie-Sorin, Carmen. 2019. "Presuppositional indefinites in French: a blocking account." Talk given at the Incontro di Grammatica Generativa 45, February, 21-23, Italy: University of Padova.

Solt, Stephanie. 2009. The semantics of adjectives of quantity. PhD Diss., City University of New York.

Stark, Elisabeth, and David Paul Gerards. This volume. "'Partitive Articles' in Aosta Valley Francoprovençal—Old Questions and New Data."

Storto, Gianluca. 2003. "On the status of the partitive determiner in Italian." In Romance Languages and Linguistic Theory 2001: Selected Papers from Going Romance 2001, edited by Josep Quer et al., 315-330. Amsterdam: John Benjamins.

Szabolcsi, Anna. 2004. "Positive polarity-negative polarity." Natural Language and Linguistic Theory 22, no. 2: 409-452. https://doi.org/10.1023/B:NALA.ooooo15791.00288 .43 .

Tovena, Lucia, Viviane Déprez, and Jacques Jayez. 2004. "Polarity Sensitive Items." In Handbook of French Semantics, edited by Francis Corblin and Henriëtte De Swart, 4O3-411. Stanford, CA: CSLI Publications. 
Van der Wouden, Ton. 1997. Negative contexts: Collocation, polarity and multiple negation. London, NY: Routledge.

Van den Wyngaerd, Guido. 1999. "Positively polar." Studia Linguistica 53, no. 3: 209-226. doi: $10.1111 / 1467-9582.00045$.

Van Geenhoven, Veerle. 1996. Semantic Incorporation and Indefinite Descriptions: Semantic and Syntactic Aspects of Noun Incorporation in West Greenlandic. PhD Diss., University of Tübingen.

Wilmet, Marc. 1977. "Antéposition de l' adjectif et variation de l' article partitive." Revue des Langues Romanes 82, no. 2, 429-437.

Zamparelli, Roberto. 2008. "Dei ex-machina: a note on plural/mass indefinite determiners." Studia Linguistica 62, no. 3: 301-327. https://doi.org/10.1111/j.1467-9582.2008 .oo149.x.

Zeijlstra, Hedde. 2004. Sentential negation and negative concord. PhD Diss., University of Amsterdam. 